\title{
O TROTE COMO UM RITUAL DE PASSAGEM: O UNIVERSAL E O PARTICULAR
}

\author{
Kimiye Tommasino \\ Leila Sollberger Jeolás
}

\section{A}

preocupação com o trote violento tem sido recorrente na vida universitária brasileira. Por um lado, existe uma expectativa dos jovens aprovados nos exames vestibulares com relação ao trote ao qual serão submetidos pelos veteranos. Por outro, algumas universidades promovem debates sobre o tema, sobretudo aquelas que se tornaram palco de trotes violentos. A morte de um calouro da Faculdade de Medicina da Universidade de São Paulo, há dois anos, acentuou a preocupação e intensificou discussões na imprensa e entre especialistas de diversas áreas do conhecimento ${ }^{1}$. Pais de calouros se preocupam, e algumas universidades proíbem o trote em suas formas tradicionais, incentivando o trote cultural. São preocupações e iniciativas legítimas, na tentativa de enfrentar o problema.

A Universidade Estadual de Londrina regulamentou a proibição do trote violento em agosto de 1999 e, este ano, instituiu em seu lugar uma gincana universitária, duas semanas após o início das aulas. $\mathrm{O}$ fato gerou polêmica entre os alunos, que questionaram a forma com que a alternativa foi proposta, sem discussões e sem participação da comunidade universitária. Cabe ressaltar aqui a necessidade de se refletir sobre o sentido e a importância simbólico-prática desse ritual em nossa sociedade, parte constitutiva da vida universitária, e ampliar o debate para toda a comunidade, o que não se fará sem dificuldades, pois envolve tema complexo, como o da violência nas sociedades atuais.

Evidentemente, não há justificativa para o assassinato, principalmente quando surge revestido de futilidade, como acontece no trote. E o exemplo mais recente da morte do calouro de medicina reverbera 
em nossa memória. Nem tampouco se justificam as humilhações, infringidas aos calouros pelos veteranos, principalmente quando ultrapassam o limite do aceitável pelo outro. Não é nossa intenção, portanto, defender simplesmente o trote como expressão históricocultural ou costume tradicional, desde a Idade Média, e tomá-la como explicação suficiente para justificar, por si só, as manifestações atuais de tal prática. Tal atitude dá margem para críticas dirigidas a algumas abordagens antropológicas reducionistas sobre o assunto. Nas abordagens atuais da antropologia, a cultura não se define como algo que se carrega e se incorpora, de um tempo a outro, ou de uma sociedade a outra, mas sim como fruto de interações dinâmicas de sujeitos sociais que atribuem sempre novos significados históricos às suas ações ou como sistemas simbólicos que adquirem sempre novos significados historicamente. Desta forma, a análise do que representa o trote atualmente, e a violência com que tem se revestido em algumas universidades, deve levar em consideração o contexto da sociedade brasileira atual, com todas as contradições aí presentes.

O tema é complexo e requer discussão cuidadosa e ampla para que, de maneira sempre aproximativa, possamos melhor compreender os sentidos subjacentes que essa manifestação histórica assume contemporaneamente, comportando múltiplas determinações.

Esperamos aqui poder contribuir, inicialmente, para o debate, trazendo algumas considerações da antropologia que, em sua tradicional tarefa de conhecer outras sociedades, intensifica o exercício de relativizar o conhecimento sobre nós mesmos, contribuindo para a compreensão da sociedade na qual vivemos.

\section{O sentido dos rituais nas sociedades tradicionais? ${ }^{2}$}

As sociedades humanas desenvolveram formas de socialização de seus membros, reforçadas, em grande parte, pelos ritos que acompanham os ciclos anuais das atividades. Ritos de Iniciação, de Passagem, de Inversão, de Rebelião, todos eles estruturas antropológicas que marcam o lugar, o estado e o status dos membros de uma coletividade (Van Gennep, 1978; Gluckman, 1974). Os ritos de passagem são também 
ritos de iniciação. Clastres (1982, p.81-82), ao discutir o assunto nas sociedades tribais, afirma que eles:

"têm por missão comunicar aos jovens um saber-sobre sua sociedade, que se prepara para acolhê-los. Isso não é tudo. Este saber, adquirido pela via iniciática, não é, na verdade, um saber sobre a sociedade e, portanto, saber exterior a ela. Ele é necessariamente o saber da própria sociedade, saber que lhe é imanente e que, como tal, constitui a própria substância da sociedade, seu Eu substancial, aquilo que ela é nela mesma. No rito iniciático, os jovens recebem da sociedade, representada pelos ordenadores do ritual, o saber daquilo que a sociedade é, em seu ser, daquilo que a constitui e a institui como tal: o universo de suas regras e de suas normas, o universo ético-político de sua lei. O ensino da lei e, em seguida, a prescrição da fidelidade a esta lei, na medida em que ela assegura a continuidade, a permanência do ser na sociedade".

Os ritos de iniciação marcam, portanto, a passagem de um status a outro, delimitando direitos, responsabilidades e deveres. Demarcam, com clareza, a aquisição de um novo status social, pressupondo a assunção de responsabilidades econômicas, civis, conjugais e familiares. Seu aspecto coletivo prepara o sujeito social para viver uma nova situação, controlando medos, angústias e inseguranças, próprias dos momentos de mudança. Isso porque os ritos de passagem tradicionais exigem uma herança a ser legada pelas gerações mais velhas, princípios éticos e estéticos e um saber sobre o passado que se projeta sobre o futuro.

Eles possibilitam uma formação no sentido mais profundo de construção do ser social, isto é, no sentido moral. Krenak (1989, p.5) fala desse processo da seguinte maneira:

"Na nossa tradição, um menino bebe o conhecimento do seu povo nas práticas de convivência, nos cantos, nas narrativas. Os cantos narram a criação do mundo, sua fundação e seus eventos. Então, a criança está ali crescendo, aprendendo os cantos e ouvindo as narrativas. Quando ela cresce mais um pouquinho, quando já está com seis ou oito anos, aí então ela é separada para um processo de formação especial, orientado, em que os velhos, os guerreiros, vão iniciar essa criança na tradição. 
Então acontecem as cerimônias que compõem essa formação e os vários ritos, que incluem gestos e manifestações externas. Por exemplo, você fura a orelha. Fura o lábio para colocar o botoque. Dependendo de qual povo a que você pertence, você ganha sua pintura corporal, seu paramento, que vai identificar sua faixa etária, seu clã e seu grupo de guerreiros. Esses são os sinais externos da formação. Os sinais internos, os sinais subjetivos, são a essência mesma daquele coletivo. Então você passa a compartilhar o conhecimento, os compromissos e o sonho de seu povo. As grandes festas se constituem em instantes de renovação permanente do compromisso de andar junto, de celebrar a vida, de conquistar as suas aventuras. Então a nossa tradição consiste, de maneira resumida, nesses eventos. A formação é isso".

Se a presença de processos rituais é universal, conhecemos melhor sua existência nas sociedades indígenas, pois nelas os rituais são longos e ocupam grande parte da vida cotidiana. Isso se deve, em parte, porque os rituais acontecem em períodos marcados pelo tempo ecológico (estações do ano, por exemplo) e implicam a afluência de todas as pessoas das mais distantes aldeias, ocasionando total alteração da vida aldeã.

É verdade que nos rituais tradicionais há violência da dor física infringida aos jovens pelos mais velhos. Mas violência que todos sofrem, ritualizada, marcando na memória a passagem efetivada e a prova de coragem para a aquisição dos novos papéis sociais exigidos pela sociedade, de maneira bem definida, a todos os seus membros. No caso da formação do homem adulto, juntamente com o aprimoramento das habilidades para o trabalho, exige-se dos meninos, nos rituais de iniciação, testes de virilidade, de força física e domínio do medo. Entretanto, Rangel (1999) lembra que a crueldade ou violência presentes nestes rituais são controlados pelos mais velhos - pais, tios, irmãos, primos ou padrinhos - que transmitem as regras e valores culturais do grupo para os mais novos. Segundo a autora (idem, p.152), eles "estão sempre atentos, fazendo-se respeitar quando julgam estar sendo excessivas as exigências com os iniciados".

Krenak (1989), ao descrever os ritos em que os meninos recebem seu nome, suas pinturas e seus paramentos (botoque labial, por exemplo), fala do sofrimento físico vivenciado como prova de coragem incentivada 
e controlada pelo grupo. No final do ritual e das festas que o acompanham, os meninos são incorporados, de fato, à sociedade, pois passam a pertencer a uma categoria de idade e a um clã. Na puberdade, todos os jovens devem passar pelo rito de iniciação para tornarem-se adultos. É agora Clastres (1982, p.80-81) quem explica a importância simbólico-prática do rito de passagem:

"Tornar-se adultoé morrer para a infância e nascer para a vida social, pois desde então os rapazes e moças podem deixar sua sexualidade expandir-se livremente. Compreende-se assim que os ritos de passagem tenham lugar, como os ritos de nascimento, em uma atmosfera dramatizada ao extremo. A comunidade dos adultos dramatiza a recusa em reconhecer seus recémiguais, sua resistência em aceitá-los como tais, finge ver neles concorrentes inimigos. Mas ela quer igualmente, por meio da prática ritual, mostrar aos jovens que, se eles sentem o orgulho de aceder à idade adulta, isto se dá ao preço de uma perda irremediável, a perda do mundo despreocupado e feliz da infância. É devido a isto que, em numerosas sociedades sulamericanas, os ritos de passagem comportam uma série de provas físicas muito penosas e uma dimensão de crueldade e de dor que torna esta passagem um acontecimento inesquecível: tatuagens, escarificações, flagelações, picadas de vespas ou formigas, etc., que os jovens iniciados devem suportar em meio ao mais profundo silêncio. Eles desmaiam, mas sem gemer. E nesta pseudomorte, nesta morte provisória (o desmaio deliberadamente provocado por aqueles que conduzem o ritual), surge claramente a identidade de estrutura que o pensamento indígena estabelece entre nascimento e passagem. Este é um renascimento, uma repetição do primeiro nascimento, que deve, consequentemente, ser precedido por uma morte simbólica".

Para o autor, o ritual de iniciação comporta "uma pedagogia profunda que vai do grupo ao indivíduo, da tribo aos jovens". A força do coletivo é inquestionável e todos devem aceitar suas leis como marcas deixadas nos corpos para que não se esqueçam de seu lugar e de seu papel como membros de uma coletividade.

Importante ressaltar que as análises do autor revelam a pedagogia indígena dirigida a todos os membros do grupo para que 
internalizem os princípios da igualdade social entre os membros da sociedade. Através das práticas rituais se externaliza essa igualdade e o corpo passa a ser a memória desse conhecimento. Para Clastres (1978, p.130), as sociedades indígenas são sociedades contra o Estado precisamente porque:

"A lei, inscrita sobre os corpos, afirma a recusa da sociedade primitiva em correr o risco da divisão, o risco de um poder separado dela mesma, de um poder que lhe escaparia. A lei primitiva, cruelmente ensinada, é uma proibição à desigualdade de que todos se lembrarão. Substância inerente ao grupo, a lei primitiva faz-se substância do indivíduo, vontade pessoal de cumprir a lei".

Nas sociedades tribais, a busca de mecanismos que garantam leis para todos, papéis sociais bem definidos, referências simbólicas mais unívocas e menor desigualdade econômica e política, faz com que elas, evidentemente, atribuam aos rituais, e mesmo à violência contida em alguns deles, uma outra dimensão e outros significados diferentes daqueles presentes nos rituais das sociedades modernas.

Por isso, os rituais são processos de formação e de socialização de todos na tradição, no conhecimento e nos compromissos do grupo. Se são universais é porque expressam coisas essenciais relacionadas à natureza humana. Podemos mesmo pensar que é através dos rituais que o homem se humaniza. Mas esta expressão se dá de diversas maneiras e com diferentes sentidos, dependendo da sociedade em questão.

Nas sociedades indígenas, de modo geral, os rituais de passagem e de iniciação são bem demarcados para todos. Apesar das diferenças existentes entre as sociedades indígenas, com tradições culturais distintas, talvez o traço comum mais significativo entre elas seja a forma horizontal de organização social, em que se encontra uma hierarquia de funções, mas não de dominação. A forma de organização simétrica não admite relações de dominação/subordinação entre os homens, mulheres, crianças, adultos e velhos, mas apenas diferenças de papéis e de funções. De acordo com Rangel (1999, p.147), em "sociedades não estratificadas em classes, como estas, os adultos serão homens e mulheres em pleno 
exercício de suas funções sociais, produtivas e reprodutivas", cujo modelo de sociabilidade se baseia na correspondência entre o ciclo de vida e as funções e papéis assumidos pelos membros da sociedade. $\mathrm{O}$ que explica que as etapas etárias sejam equivalentes a posições sociais bem definidas.

Neste sentido, compreende-se porque, nas sociedades indígenas, os rituais atuam de maneira bem demarcada, a definir papéis e funções para os seus membros. Socializam e, ao mesmo tempo, atuam, igualmente, como forma de regular a desordem, potencialmente disruptiva se não houver mecanismos de controle pelo social.

Neste tipo de organização horizontal, encontramos outro conceito de homem, de ser humano que não necessita se individualizar para diferenciar-se dos outros, pois cada adulto vê o outro como igual, ou seja, se reconhece no outro. As marcas de cada um, como disse Krenak, são a essência mesma do coletivo.

Diversamente, nas sociedades estratificadas, afirma Rangel (1999, p.147), "os adultos não serão somente homens e mulheres, serão cidadãos, com maior ou menor poder de interferência política, exercerão profissões variadas, terão poder aquisitivo diferenciado em conseqüência de pertencer a uma determinada classe social, como é o caso, por exemplo, das sociedades capitalistas".

Em tais contextos, os rituais, pulverizados e fragmentados, não se deixam ver com facilidade e tornam-se, na maior parte das vezes, objetos de consumo, substituídos com rapidez e ao sabor das modas. Seu poder de transmitir legado das gerações anteriores, saber sobre a sociedade, sobre o lugar e o status dos sujeitos sociais e de controlar impulsos individuais disruptivos (o da violência, por exemplo) é certamente muito menor do que o do ritual nas sociedades tradicionais.

Além da violência, outro aspecto dos ritos deve ser lembrado porque está também presente no trote, aqui analisado enquanto ritual. Trata-se da zombaria ${ }^{3}$. Nos rituais de inversão ou de rebelião, analisados por Gluckman (1974) em sociedades tribais africanas, a zombaria é parte importante do processo. Através dela e do princípio da inversão, revertese a ordem da sociedade: príncipes são despojados de suas roupas e proteções e perambulam pelas ruas como mendigos, ouvindo músicas 
desrespeitosas cantadas por seus súditos; mulheres assumem em público comportamentos próprios dos homens. Os membros destas sociedades ritualizam e explicitam conflitos e tensões latentes, expressões de desigualdades reais por eles vivenciadas. No Brasil, DaMatta (1979) analisa princípios de inversão ritualizados no carnaval, também expressão de desigualdades sociais produzidas pela sociedade.

Balandier (1982) analisa com profundidade a presença do Bobo da Corte ou do Bufão, do Trickster (trapaceiro) e de outros deuses e heróis de diferentes tradições culturais que, com humor e zombaria, transgridem e invertem a ordem social, explicitando os mecanismos do poder, concebido como um jogo dramático. Ordem e desordem se interpenetram. Por um lado, o exagero, a sátira, a paródia e a zombaria permitem a crítica à ordem social. Se o jogo da verdade, e a explicitação das desigualdades, é um jogo perigoso, o Bufão tem licença para realizálo, pois a via cômica o torna menos ofensivo e adquire função catártica de liberação de tensões com a segurança de que no ritual a transgressão é limitada. Por outro lado, essa capacidade ofensiva explicita o fato de que o poder e suas hierarquias podem ser depreciados, revertidos e transformados. Essas figuras da inversão expressam uma reivindicação de liberdade, contra os constrangimentos e a força da ordem. Lembramnos, de um lado, o que sucederia a uma sociedade se suas normas e proibições se dissolvessem mas, de outro, lembram-nos, igualmente, que é possível transformá-las.

Nas sociedades tradicionais, a crítica, a transgressão, a violência se liberam e depois se domesticam na dramatização coletiva dos rituais, pautados pela tradição. Já as sociedades modernas, diz Balandier (1982, p.74):

"parecem ter perdido o uso de um certo número de mecanismos capazes de realizar a domesticação da desordem - no sentido técnico do termo, e não policial. Elas são, no curso de um desenvolvimento rápido e desordenado, geradoras de danos, embaraços, disfunções e desajustamentos. Nelas, parece em via de se realizar uma dupla polarização: num dos extremos, a submissão à ordem das coisas, animada tão-somente pela competição pelos bens e pelos signos; no outro extremo, a recusa radical, podendo levar à exaltação e à prática da violência 'pura' “. 


\section{A sociedade moderna: fragmentação e pulverização dos rituais}

Os rituais de passagem e de iniciação já estiveram presentes em nossa sociedade de forma mais demarcada. Apesar da distância social e histórica, os chamados segmentos tradicionais de nossa sociedade sempre marcaram bem a passagem dos jovens à idade adulta. Até o primeiro quarto deste século, os jovens tinham diferentes ritos de passagem, que simbolizavam as transformações ocorridas na puberdade e a aquisição de novos papéis sexuais e sociais: a primeira festa ou baile, o primeiro emprego, a primeira relação sexual, o casamento, prenunciavam a passagem para a maturidade. Nas sociedades camponesas, tal como nas sociedades indígenas, os jovens, quando entram na puberdade, tanto os rapazes quanto as moças, passam à fase adulta, por isso o casamento precoce, se comparado ao que acontece com os jovens das sociedades urbano-industriais. São momentos em que os jovens assumem papéis sociais e responsabilidades civis.

Atualmente, embora menos visíveis e demarcados, os procedimentos rituais ainda permeiam a vida cotidiana: quando nasce uma criança, ela é cercada de cuidados e atenções específicas. Alguns são procedimentos exigidos pela atividade pediátrica, mas outros extrapolam seu sentido utilitário ou pragmático. As visitas de parentes e amigos mais próximos, o nome escolhido, o batismo, são procedimentos rituais. Os meninos podem ganhar do pai uma camiseta do time preferido e as meninas, ter suas orelhas perfuradas para colocar um brinco. Outros acontecimentos na biografia de cada indivíduo, como as festas de aniversário, o primeiro dia de aula, a primeira comunhão, são alguns dos possíveis momentos ritualizados em nosso cotidiano. Aparentemente sem importância por caracterizarem um "costume", esses fatos rituais marcam indelevelmente o longo trajeto da criança à idade adulta, introjetando, em cada um, valores da sociedade.

Entretanto, os ritos tradicionais vêm perdendo, cada vez mais, seu valor de nítida demarcação entre a infância e a idade adulta. Observase o fenômeno da erotização precoce das crianças, através dos meios de comunicação de massa, que transformam o público (infantil e adulto) em consumidores potenciais; há origens sociais e culturais diferentes, 
convivendo no mesmo espaço urbano e, portanto, influências, códigos e valores diversos; e a rapidez com que as mudanças ocorrem, atualmente, nos faz pensar na afirmação de René Clair (citado por Le Breton, 1991, p.102): "a herança está sem testamento para cada geração". Atualmente, as relações entre as gerações antecedentes e as seguintes apresentam-se quase sem continuidade. As gerações antecedentes estão perdendo uma parte importante de sua capacidade de informação e de formação e, consequentemente de sua autoridade. Balandier (1976, p.248) expressa a efemeridade e a rapidez das mudanças atuais, citando a comparação que Mary Douglas faz desta época com a das antigas aventuras pioneiras:

"Hoje, quem quer que tenha nascido e se educado antes da Segunda Guerra Mundial, é semelhante a um imigrante no tempo, do mesmo modo que seus ancestrais o foram no espaço, tentando ajustar-se a condições desconhecidas de vida numa nova era".

Os jovens se confrontam com uma multiplicidade de papéis sociais, de valores e de referências, ao mesmo tempo em que são limitados por pressões sociais e econômicas. De um lado, as dificuldades profissionais e a ameaça do desemprego; de outro, a inadequação entre as suas aspirações e desejos e as possibilidades oferecidas pela sociedade. Sua angustia é ampliada face aos apelos do consumismo.

O que se observa hoje são rituais pulverizados e múltiplos, em consonância com origens sociais e culturais diferentes e mutantes ao sabor das modas, por isso, provisórios e pouco enraizados, mais ligados aos ciclos de consumo. Perdida a força vital dos rituais tradicionais, cabe ao próprio jovem buscar formas outras de simbolização, ora com, ora sem a ajuda da família, ora de maneira solitária, ora em grupo (as "galeras", as gangues).

Nos rituais de nossos dias, as normas particulares aos grupos não encontram respaldo nos costumes nem se sustentam na tradição. Hoje, nenhum rito proporciona referências e valores estáveis e unívocos. Ao contrário, o indivíduo vem sendo solicitado, cada vez mais, a contar consigo próprio na elaboração de sentido para a existência. Os comportamentos e as lógicas que os sustentam se diferenciam, as 
circunstâncias variam muito, as referências e os valores se multiplicam e as informações, em excesso, se difundem com muita rapidez. Diante dessa realidade fluída e em rápida transformação, os jovens sentem dificuldade em situar-se no mundo. Apesar da multidão que os cerca (nos shopping centers, nos aeroportos, nas auto-estradas), vivem a solidão e sofrem a crise identitária, conforme a análise de Balandier (1994).

Os jovens se vêem, assim, diante da necessidade de buscar, por si próprios, servindo-se de seus próprios recursos e, ainda, na dependência das circunstâncias vividas, o que antes a sociedade garantia pelas formas ritualizadas e sancionadas no coletivo.

É verdade que o indivíduo de hoje ganhou mobilidade e autonomia em relação à sua rede de parentesco e às pressões e coações próprias das sociedades tradicionais, mas, ao mesmo tempo, ele vem encontrando dificuldades de inserção nas sociedades contemporâneas. Como revela Douglas (1994, p.15), num mundo globalizado,

"Sair da comunidade local significa desafiar suas tiranias, deixar pressões por vezes pesadas, mas, eu gostaria de acrescentar que essa liberação da pequena comunidade significa também perder as velhas proteções. $O$ mercado nos suga para fora de nosso nicho acolhedor, colocando-nos no sistema mundial - móvel-e, deixando-nos livres, ele deixa-nos expostos. Sentimo-nos vulneráveis".

A necessidade dos jovens atuais de pertencerem a um grupo provém dessa situação. A constituição de gangues e de "galeras" nas grandes cidades está relacionada a esse novo contexto: eles buscam referências, segurança e, inclusive, proteção física e garantia de sobrevivência, no caso daqueles jovens inseridos em ambientes mais violentos.

Com o processo crescente, desigual e complexo de urbanização e de industrialização, introduziram-se profundas mudanças nas instâncias da religião e da família, enfraqueceram-se, progressivamente, os laços de parentesco, as relações de vizinhança, as associações voluntárias, as festas de bairro e outras formas de sociabilidade e socialização. Paralelamente a esta ruptura, elaboram-se novas formas de sociabilidade para responder à necessidade de experiência comunitária: bailes funks, 
grupos de rock, rappers, pagodeiros, metaleiros, surfistas, grafiteiros (Zaluar, 1997). No mundo atual, em que os valores comunitários cada vez mais se enfraquecem, os piercings, tatuagens, brincos e alfinetes constituem linguagens, expressões de pertencimento e de liderança, ethos de grupo, mensagens ávidas para tentativas de comunicação.

A partir dos anos 80, proliferaram, no país, grupos de jovens que se articulam em torno de um estilo de música, de roupa e de adereços, de posturas e comportamentos em relação ao lazer. Todos remetem às formas arcaicas de agregação e de sociabilidade ora revisitadas, possibilitando a recriação de ethos grupais, tão necessários ao processo de identidade do jovem. Formas de associação em grupos, com normas, códigos e símbolos próprios. Atualmente, segundo Jeammet (1993), o grau de insegurança e de angústia do jovem pode ser medido, se levarmos em conta o desafio constante que lhe é imposto pelos tempos atuais: possibilidades inigualáveis de consumo e êxito pessoal, impensáveis em toda a história da humanidade, porém inalcançáveis para a maioria. A este desafio, os jovens respondem, por vezes, através de condutas de negação e de auto-destruição.

\section{Os sentidos do trote: a universidade e seu caráter excludente}

Os dois aspectos presentes nos rituais das sociedades tradicionais - a violência e a zombaria - ganham outros contornos no contexto das sociedades atuais, acima esboçados, e somente uma análise mais aprofundada possibilitará melhor compreensão do trote entre nós.

Na Idade Média, o acesso à universidade era buscado como chance de ascensão social para burguesia e camponeses, estes últimos, sobretudo, alvo de desprezo e de discriminação, pois considerados rústicos, quase selvagens. A inserção na universidade significava a possibilidade de aquisição de um novo status social, marcado pelo ritual do "trote" (Coltro, 1999, p.135).

Ainda hoje, o trote nas universidades se apresenta como ritual, no qual se fazem presentes elementos da festa e da prova iniciática, do sagrado e do profano, da ordem e da desordem. 
Mas a realidade atual é complexa. Frente a falta de perspectivas profissionais para os jovens em nosso país, o ensino universitário tem sido buscado como garantia de um futuro mais estável. Como resultado da exclusão social e da pauperização crescentes para a maioria da população, a universidade passou a ser representada como um "passaporte" para se alcançar melhores condições de vida, mas, ao mesmo tempo, as vias de acesso tornam-se cada vez mais restritas. A competitividade do mercado exigente, o forte apelo consumista, criando desejos não realizáveis, são pressões sofridas por todos os jovens, universitários ou não.

Ocorre que o ensino público não garante vaga a todos, e a cada ano observa-se aumento de candidatos que se deslocam para várias universidades brasileiras para participarem de vestibulares concorridíssimos. Embora não haja pesquisa sistemática, sabe-se de jovens que participaram de dezenas de vestibulares, em várias universidades do país, para obterem vaga nos cursos de medicina, engenharia, odontologia, veterinária e outros. Na verdade, dependendo do curso, o jovem é obrigado a prestar vestibular em muitos locais, levando, por vezes, anos seguidos para conseguirem uma vaga, numa verdadeira maratona.

O enfrentamento dos exames vestibulares ensina ao jovem que a universidade não é para todos e que os cursos mais disputados estarão disponíveis para um número mais reduzido ainda. Por vezes, os jovens deverão abdicar de uma profissão desejada, em troca de outra alternativa, gerando frustração e sentimentos ambíguos.

Os jovens aprendem a natureza excludente da sociedade na qual vivem. Assimilam que o vestibular é uma forma violenta de exclusão. $\mathrm{O}$ jovem vestibulando que quiser obter vaga em um curso concorrido deverá enfrentar noites sem dormir, passeios e lazer abdicados, pressão psicológica e familiar, estresse. Pode-se compreender que, para os que passaram, o momento do trote represente um verdadeiro desabafo, catarse e expressão da pressão contida nos últimos tempos. As "festas" que se seguem ganham nova proporção, tendo, em alguns casos, gerado excessos, violências e morte. A sociedade brasileira ainda não se refez do susto e do choque pela morte do calouro ocorrida na Faculdade de Medicina da USP, no ano passado. 
Devemos nos deter neste aspecto. A maioria dos trotes violentos tem ocorrido em cursos cujo acesso é bastante competitivo, como as faculdades de medicina. Além do esforço e dos sacrifícios anteriores para garantir uma vaga, o curso de medicina é extenuante e desgastante e ao aluno é exigido um desempenho individual que só se consegue com muita disciplina. Além do aspecto de competitividade e da pressão exigida, há outro elemento a ser considerado, segundo Ribeiro (1999, p.153), que é o fato de serem cursos que "lidam com experiências humanas radicais, como a morte, para o qual os estudantes nunca foram preparados". Já no primeiro ano, os alunos defrontam-se com a dor, o sangue, o sofrimento e desespero de pacientes e familiares, a impotência, a morte.

Nossa sociedade vem afastando a morte de seu horizonte, assim como a perda e o sofrimento, sistematicamente banidos do imaginário da cultura ocidental. Para os sofrimentos - do corpo e da alma - todos os medicamentos possíveis e, para a morte, a sua própria banalização, através de imagens fluídas e fugidias, em tempo real, que passam pelos nossos olhos através dos meios de comunicação e impedem-nos de reagir a ela, de senti-la, de sofrer por suas vítimas, transformadas em irreais, não palpáveis, dada a velocidade e o encadeamento improvável com que nos são apresentadas. Paradoxo de nossos tempos: por um lado, nos afastamos da morte, transferindo-a para fora do âmbito doméstico, para locais especializados em velórios (do qual as crianças não devem participar) e na preparação dos mortos, maquiando-os, da melhor maneira possível, para que pareçam vivos; por outro lado, somos como que atraídos por acidentes, catástrofes, crimes, quando os traços da morte se apresentam com todas as suas tonalidades.

Como e para onde estaremos canalizando esta nossa necessidade antropológica de dar sentido à morte, uma vez ela é o significante maior, contraponto da própria vida? E o sofrimento, como escapar deste componente necessário ao nosso processo de humanização? Sem falar da impotência, que tem se tornado, em nossos tempos, e cada vez mais, sinônimo de fracasso, este companheiro inadmissível ou presença inaceitável nas sociedades atuais cujo traço, por excelência, é o da competição.

A mera proibição do trote em suas modalidades violentas, afirma ainda Ribeiro $(1999,153)$, “embora seja uma medida correta, não vai além 
da superfície de um problema profundo que diz respeito ao modo como nossa sociedade [não] pensa sua relação com a morte", a dor, o sofrimento, a impotência, as desigualdades, as injustiças, a violência.

Nosso papel deve ser, justamente, o de criar e possibilitar espaços para isto, para reflexões profundas, coletivas e públicas.

Se o trote constitui-se um ritual de passagem para ínfima parcela de jovens que têm acesso à universidade brasileira, cuja função é receber e prepará-los para uma nova situação social, o papel dos veteranos seria o de introduzir os calouros neste universo, transmitindo informações e apresentando experiências vividas sobre o mundo acadêmico e criando um espaço para simbolizar o novo status social. Nos trotes violentos, os veteranos perdem de vista este seu papel e extrapolam as humilhações, exercendo sua força e poder.

Outro elemento presente no trote, a zombaria, que expressa a transgressão e a inversão, formas de ritualizar e explicitar desigualdades, pode também adquirir novas conotações neste ambiente de pressão, de competição e de estresse descrito. Por um lado, os jovens calouros "pintados" e "transvestidos" de mendigos, são obrigados pelos veteranos a sair pelas ruas da cidade, "pedindo esmolas". O processo de inversão se evidencia: jovens, de um modo geral, privilegiados, comportando-se como mendigos, sujos, e submissos à obediência dos veteranos, são apresentados à população como "pobres" e "burros" para serem reconhecidos pela sociedade. Por outro lado, a subjugação dos calouros pelos veteranos também se apresenta como inversão: de submetidos que são, como alunos, às normas e regras da instituição acadêmica, com suas hierarquias, prazos e avaliações, os veteranos podem, no trote, inverter a situação e submeter os calouros às suas regras e demandas. Mas nesta inversão, em alguns casos, a humilhação pode extrapolar os limites do permitido pelo outro, pode beirar a vingança e o revanchismo por todo sofrimento anteriormente experimentado pelos veteranos para chegar onde estão. Não devemos nos esquecer que no ritual do trote não há a presença de pessoas mais velhas que transmitem conhecimentos, valores e regras para os mais novos, como acontece nos rituais das sociedades tradicionais.

Não estaria igualmente atuando no trote, enquanto ritual, o "ethos da virilidade" ou da força, outro elemento presente em muitas manifestações da vida social: nas brigas entre jovens armados (as armas, 
sobretudo as de fogo, tem se tornado símbolo de força e poder), nas lutas entre grupos de jovens, na guerra de força entre gangues e na "adrenalina" buscada nestes jogos de força?

Embora sem poder desenvolver estas idéias no espaço do presente artigo, vale a pena ressaltar também o papel do álcool entre os jovens em nossa sociedade. Esta substância lícita, e cujo consumo é amplamente estimulado pela publicidade e aceito nos diversos segmentos da sociedade, tem sido a causadora, ou pelo menos um componente importante presente no elevado número de graves acidentes e de mortes violentas ocorrida entre os jovens no país. Não há controle social que delimite as ocasiões e a quantidade a ser consumida, como acontece com as drogas utilizadas em vários rituais mágico-religiosos. Vale refletir se os excessos cometidos nos trotes, misto de extravasamento de tensão e de revanchismo, não teriam o álcool como outro aliado. Ingerido de forma descontrolada, o álcool não ajudaria a liberar controles impostos e necessários para convivência em sociedade, fazendo emergir todos esses elementos anteriormente apontados e potencialmente presentes nos trotes? Neste contexto, como garantir o respeito aos limites do outro?

$\mathrm{O}$ que distinguiria, portanto, fundamentalmente, os ritos modernos dos tradicionais seria o respaldo do coletivo a dar limites, a controlar os excessos, o não aceitável.

Dumont (1985) descreve dois tipos de ideologia que distinguiriam as sociedades humanas. Designa "holismo" a ideologia que valoriza a totalidade social e negligencia ou subordina a pessoa a essa totalidade e, "individualismo" a ideologia que valoriza o indivíduo, ficando a totalidade social negligenciada ou subordinada ao primeiro. Neste sentido, o autor observa que o individualismo é um traço importante, na configuração de traços que constitui a ideologia moderna.

O individualismo, importante característica das sociedades modernas, está presente na busca de significados pelo próprio indivíduo, segundo Balandier(1994) e Le Breton (1991). Em uma sociedade excludente, que estimula a competitividade e o desempenho pessoal, com um ritmo acelerado nas mudanças e de apelo ao consumismo, o indivíduo não se sente respaldado pelo social, pelos enraizamentos e tradições legadas pelo coletivo, mas é levado a buscar, por si só, os significado de sua existência. 
Os ritos de passagem tradicionais exigem uma herança a ser legada pelo grupo dos mais velhos que, ao organizarem a cerimônia, transmitem uma linha de orientação, um saber sobre o passado que se projeta para o futuro. As sociedades atuais, entretanto, ao instaurarem "uma permanência do provisório", levam os jovens a perderem, de forma crescente, o contato com a geração que os precedeu. A diferença é que as normas, os códigos e os valores presentes nos rituais de iniciação das sociedades tradicionais, porque coletivos, tinham seus significados compartilhados socialmente. Como já citamos, nos pulverizados rituais de nossos dias, as normas, particulares aos grupos, não encontram respaldo nos costumes nem se sustentam na tradição. Hoje, nenhum rito proporciona referências e valores estáveis e unívocos. Ao contrário, o indivíduo vem sendo solicitado, cada vez mais, a procurar por si próprio, servindo de seus próprios recursos e na dependência das circunstâncias vividas, o que se produz(ia), fundamentalmente, pelo coletivo. Os comportamentos e as lógicas que os sustentam se diferenciam, as circunstâncias variam muito, as referências e os valores multiplicam-se e as informações, em excesso, se difundem com enorme rapidez, permitindo ao indivíduo mudar de posição ou de status social, desempenhar vários papéis sociais, ser influenciado por inúmeras referências e valores, ser bombardeado por informações e apelos de consumo ao longo de sua vida, numa composição heteróclita e complexa. É como se o indivíduo tivesse que perguntar, a todo momento, ao vasto repertório de conhecimentos, de representações e de significados acumulados ao longo da própria vida, qual valor atribuir às experiências sociais, já que os ritos não o fazem mais satisfatoriamente.

\section{A violência nos trotes}

As práticas violentas observadas em alguns trotes do país mostram que a violência é um fenômeno complexo, apresenta múltiplas dimensões e exige uma compreensão dos significados que encerra. A violência está presente tanto no quotidiano de nossas vidas como em momentos rituais, os quais deveriam se constituir em formas instituídas de agregação social e de reforço da solidariedade entre os grupos e de comunhão de valores e princípios entre os participantes. Momentos em 
que tensões sociais são dramatizadas e simbolizadas, conflitos explicitados, perigos apaziguados, a violência controlada e a desordem prevenida. Entretanto, os trotes violentos apresentam características próprias de nossa sociedade, possibilitando a expressão de comportamentos individualizados, excessos descontrolados e desrespeito aos limites do grupo e do outro. As regras não são dadas e nem respeitadas, como acontece nas sociedades indígenas. Rompe-se a tensão equilibrada entre ordem e desordem. Esta última, potencializadora neste frágil equilíbrio, torna-se perigo, descontrole, violência.

Dada a complexidade do fenômeno, que adquire contornos próprios nas sociedades modernas, impossível enfrentar este problema apenas por decreto de proibição. A violência na cidade e no campo, em nosso país, é violência de natureza estrutural, numa sociedade geradora de múltiplas formas de exclusão e marginalização crescentes, ocorridas em seu processo de desenvolvimento. Milhares de jovens chegam à idade adulta e não conseguem inserir-se no mercado de trabalho, afunilando drasticamente o acesso à escolarização seriada e impedindo sua plena formação e preparo para efetiva participação como membro da sociedade.

É urgente, pois, enfrentar o problema da violência na sociedade brasileira e, em relação ao tema que nos suscitou preocupação e nos levou a propor estas reflexões para contribuir com o debate. Temos que enfrentá-lo, coletivamente, num debate aberto, envolvendo a comunidade universitária e a sociedade.

Se todo rito é espaço simbólico de expressão da tradição e, ao mesmo tempo, de (re)criação do novo, se ele absorve a desordem potencial, introduzindo-a na ordem social e canaliza forças disruptivas, dramatizando-as e simbolizando-as, é possível esperar que o trote, enquanto rito, permanente e historicamente reelaborado, possa continuar a funcionar como rito socializador.

Cabe a nós, cientistas sociais, contribuir para a compreensão da violência manifesta em algumas formas de trote e para a elaboração de propostas que criem, ampliem espaços necessários para a discussão de idéias, valores e sentimentos em que medos e inseguranças possam ser compartilhados e os elos sociais reforçados.

Vale registrar a forma criativa e alternativa com que o curso de artes da Universidade Estadual de Londrina possibilitou espaço para 
ritualização do trote na Semana do Calouro, que antecedeu o carnaval, organizando uma oficina de fantasias no calçadão do campus universitário. Através das fantasias, alguns elementos dos rituais se fizeram presentes: a (re)presentação de papéis sociais e a inversão dos mesmos (homens vestidos de mulher, ricos de pobres e vice-versa). Além da atuação do lúdico, da imaginação e da criação, os jovens calouros puderam externar e compartilhar com os veteranos este momento preparatório de adentrar o universo da academia. Exemplo de trote como um espaço cultural e sem violência.

Certamente não devemos perder a oportunidade de refletir, dentro e fora da universidade, o trote violento como um desdobramento, não desejável, de um rito de passagem, enquanto forma de linguagem e de socialização dos jovens na comunidade universitária. Desdobramento este, produzido por características de nossa própria sociedade e cultura atuais. Proibi-lo seria o mesmo que eliminar apenas a superfície ou o sintoma de algo mais sério e profundo, a violência gerada pelo nosso sistema social.

Como linguagens de comunicação, gostaríamos de ver os ritos comunicarem a potência do coletivo e do social. Expressão da natureza humana, o rito é linguagem metafórica que comunica para "dentro", para o próprio grupo, e para "fora", para outros grupos, para a sociedade, linguagem de sociabilidade e de socialização que pode ajudar a elaborar pressões, superar barreiras e transpor limites.

\section{Notas}

${ }^{1}$ Ver debate publicado na revista Interface. Comunicação, Saúde, Educação. Botucatu/ Unesp, v.3, n.5, Botucatu, SP: Fundação UNI, 1999.

${ }^{2}$ Balandier (1987, p.8) utiliza os termos sociedades tradicionais e sociedades modernas para marcar as diferenças entre a forma de transmissão da tradição e as formas de comunicação social. Nas primeiras, prevalece a oralidade e a comunicação é local e pouco expansiva e se dá, de modo geral, de forma direta entre as pessoas. Nas segundas, as redes de comunicação instrumentalizam as relações sociais e os meios de comunicação estão se generalizando e acompanham as mudanças tecnológicas, acarretando modificações nas formas das relações sociais e na produção atual das representações ou das visões de mundo.

${ }^{3} \mathrm{O}$ dicionário Aurélio define o trote como zombaria a que veteranos das escolas sujeitam os calouros (...); vaia, intriga, caçoada, troça. 


\section{Referências Bibliográficas}

BALANDIER, G. Antropo-lógicas. São Paulo: Cultrix, 1976.

BALANDIER, G. O poder em cena. Pensamento político. Brasília: Editora da Universidade de Brasília, 1982 (Coleção Pensamento Político, 46).

BALANDIER, G. Images, images, images. Cahiers Internationaux de Sociologie. Paris, v.82, jan/jui, 1987, pp. 7-22.

BALANDIER, G. Le dédale: pour en finir avec le XXe. siècle. Paris: Fayard, 1994.

CLASTRES, P. A sociedade contra o estado. R.J.: Francisco Alves, 1978.

CLASTRES, P. Arqueologia da violência. Ensaios de antropologia política. São Paulo: Brasiliense, 1982.

COLTRO, M. Trote e cidadania. Interface. Comunicação, Saúde, Educação. V.3, n.5, Botucatu, SP: Fundação UNI/Unesp, 1999, pp. 135-136.

DAMATTA, R. Carnavais, malandros e heróis: para uma sociologia do dilema brasileiro. R.J.: Zahar, 1979.

GLUCKMAN, M. Rituais de rebelião no sudeste da África. Cadernos de antropologia. Brasília: UNB, n.4, 1974.

JEAMMET, P. L'adolescence est-elle un risque? In: TURSZ, A. [et al.] (orgs.) Adolescence et risque. Paris: Syros, 1993.

KRENAK, A. Receber sonhos. Revista trimestral do PT. São Paulo, Ano II, n.7, jul/ag/set., 1989, pp. 2-13.

LE BRETON, D. Passions du risque. Paris: Métailié, 1991.

RANGEL, L. H. Da infância ao amadurecimento: uma reflexão sobre rituais de inciação. Interface. Comunicação, Saúde, Educação. V.3, n.5, Botucatu, SP: Fundação UNI/Unesp, 1999, pp. 147-152.

RIBEIRO, R. J. O trote como sintoma: a dor de lidar com a dor alheia. Interface. Comunicação, Saúde, Educação. V.3, n.5, Botucatu, SP: Fundação UNI/Unesp, 1999, pp. 153-160.

VAN GENNEP, A. Os ritos de passagem. Petrópolis: Vozes, 1978 (Antropologia, 11).

ZALUAR, A. A guerra privatizada da juventude. Folha de São Paulo, São Paulo, 18/05/1997, Caderno Mais. 


\section{Resumo}

O texto objetiva contribuir com o debate atual sobre o trote violento, intensificado após a morte de um calouro de medicina há dois anos, fato que acirrou a discussão na imprensa e entre profissionais de diferentes áreas do conhecimento. Cabe ressaltar a necessidade de se refletir sobre o sentido e a importância simbólico-prática desse ritual em nossa sociedade - parte constitutiva da vida universitária - e ampliar o debate para toda a comunidade universitária, o que não se fará sem dificuldades, pois envolve tema complexo, como o da violência nas sociedades atuais.

Palavras-chave: trote universitário; rito; violência; sociedade tradicional; sociedade moderna; holismo; individualismo.

\section{ABSTRACT}

The purpose of this text is to stimulate and contribute towards a more intense debate about the violent hazing _ a theme which has been sporadically broached and retrieved _ by the press and professionals from different flelds of knowledge, after the death of a freshman from the Medicine course, two years ago. It is worth pointing out the necessity of reflecting upon the sense and the symbolic-practical importance of this ritual in our society _ an essential part ofthe university life and expand the debate for the internal coniniunity and sectors of society. Tbis will not happen without difilculties for it involves a complex subj etc, with multiple determinations such as the violence in today's societies.

Key-words: university hazing; rite; violence; traditional societies; modern societies; holism; individualism. 